IP Periodica Polytechnica

Mechanical Engineering

62(1), pp. 10-15, 2018

https://doi.org/10.3311/PPme.10606

Creative Commons Attribution (i)

RESEARCH ARTICLE

\section{Costs Analysis of Circulation Pumps for Heating of Residential Building}

\author{
Ján Takács ${ }^{1}, Z_{\text {uzana }}$ Straková $^{1}$, Lukáš Rácz ${ }^{2}$
}

Received 10 February 2017; accepted after revision 01 December 2017

\begin{abstract}
Circulation pumps are mechanical devices, which are used to create the overpressure required for the transportation of a heat-transfer medium in heating technology as well as in other related technologies.

In a circulation pump the mechanical energy generated by the drive machine - an electric motor - is transformed to hydraulic energy, which consists of kinetic and static energy. In the pipeline of a heating system circulation pumps represent a source of hydraulic energy (positive differential pressure), which is consumed to transport the heat-transfer medium. During the flow, the heat-transfer medium puts up resistance to the so-called passive resistors, which consist of pressure losses from friction in the pipes and pressure losses due to local resistance.

In this article the authors describe the research, which is based on a case study. They analyze the effect of a circulation pumps on the investments and operating costs in a residential building. Different types of circulation pumps, ranging from the most unfavorable to the optimal, were selected.
\end{abstract}

\section{Keywords}

heating, circulation pump, pumping technology, operation costs

\footnotetext{
${ }^{1}$ Department of Building Services, Faculty of Civl Engineering,

Slovak University of Technology in Bratislava,

81005 Bratislava, Radlinského 11, Slovak Republic

${ }^{2}$ TZB - PLUS, 98401 Lučenec, V.V. Majakovského 2361/B, Slovak Republic

${ }^{*}$ Corresponding author, e-mail: zuzana.strakova@stuba.sk
}

\section{Introduction}

Circulation pumps are used in heating technology to create the overpressure required to overcome the hydraulic resistance of a heating network from the heat source, through the pipeline system, to the last heating element or residential circuit. The most widespread heat-transfer medium is water (hot water up to $110^{\circ} \mathrm{C}$ ). Heating systems or individual circuits require the pumps to generate low-to-medium pressure at relatively large mass flow rates. Centrifugal hydrodynamic pumps with electric motors are the best choices in order to fulfill these requirements. In smaller heating systems so-called inline pumps are built into the pipeline. The performance requirements and pump characteristics are very different and vary depending on the characteristics of the heating system. There are different types of pumps used in technical practice, which differ in their designs and hydraulic and material solutions.

\section{Main parameters and basic terms of pumping technology}

The main pump parameters, which determines the size of the connecting throats, are the mass flow rate $M_{h}(\mathrm{~kg} / \mathrm{h})$, operating pressure $\Delta p_{p}(\mathrm{kPa})$, specific energy $Y(\mathrm{~J} / \mathrm{kg})$ and transportation head $H\left(\mathrm{~m}_{\mathrm{wc}}\right)[1,2]$.

- The pump mass flow rate $\boldsymbol{M}_{\boldsymbol{h}}(\mathrm{kg} / \mathrm{s}$ or $\mathrm{kg} / \mathrm{h})$ is defined as the quantity of fluid, which is transported by the pump from the suction side to the outlet side at a certain time unit. In terms of the pump operation, it is necessary to define the volumetric flow rate at which the pump has the best rate of efficiency. This flow is a basic calculation parameter of the pump along with the speed $n_{a}$, depending on the power of the unit and the properties of the heat-transfer medium: the specific density $\rho$ and viscosity $\mu$. The mass flow rate of the heating system is given by:

$$
M_{h}=\frac{Q}{\theta_{p}-\theta_{v}} \times 0.86
$$

where:

$M_{h}$ - pump mass flow rate $(\mathrm{kg} / \mathrm{h})$,

$Q$ - heat output, which a heating system has to supply (W), 
$\theta_{p}$ - temperature of the heat-transfer medium in the flowin pipe $\left({ }^{\circ} \mathrm{C}\right)$,

$\theta_{v}$-temperature of the heat-transfer medium in the return pipe $\left({ }^{\circ} \mathrm{C}\right)$,

0.86 - constant gear (-).

- The operating pressure $\Delta p_{p}(\mathrm{~Pa}$ or $\mathrm{kPa})$ is an indicator which reflects the amount of the energy handed over to a unit of weight of the heat-transfer substance. In older scientific literature, the transportation head $H\left(\mathrm{~m}_{\mathrm{wc}}-\mathrm{me}-\right.$ ter of water column) was used, which was enforced by the pump manufacturers. The relationship between $H$ and $\Delta p_{p}$ is $1 \mathrm{~m}_{\mathrm{wc}}=10 \mathrm{kPa}$. Pump manufacturers give either the operating pressure $\Delta p_{p}$ or the transportation head $H$. The resulting pump working pressure is calculated as:

$$
\begin{gathered}
\Delta p_{p}=\Delta p_{f r}+\Delta p_{j o}+\Delta p_{r a} \\
\Delta p_{p}=\sum(R \times l)+\sum Z+\Delta p_{r a}
\end{gathered}
$$

where:

$\Delta p_{p}$ - operating pressure of the pump (Pa),

$\Delta p_{j o}$ - pressure drop by unit of resistance $(\mathrm{Pa})$,

$\Delta p_{f r}-$ the pressure drop by friction in the pipe $(\mathrm{Pa})$,

$\Delta p_{r a}$ - the pressure drop of the regulation fittings $(\mathrm{Pa})$,

$R$ - differential pressure $(\mathrm{Pa} / \mathrm{m})$,

$l$ - lenght of the pipe section $(\mathrm{m})$,

$Z=\Delta p_{\text {j.odp }}-$ pressure drop from the resistance embedded in the pipeline $(\mathrm{Pa})$.

- The physically correct qualitative indicator of the pump is the specific energy $\boldsymbol{Y}(\mathrm{J} / \mathrm{kg})$, which is defined as the energy transferred by the pump per unit of the weight of the heat-transfer medium. It is equal to the difference between the input and the output of the specific energy. The nominal specific energy $Y_{a}$ is bonded to the nominal mass flow rate and nominal speed $n_{n}$ [3].

The working characteristics of the pump represent the variations of the main parameters of the pump, the mass flow rate $M_{h}(\mathrm{~kg} / \mathrm{h})$ or the volume flow $V_{h}\left(\mathrm{~m}^{3} / \mathrm{h}\right)$, from the operating pressure $\Delta p_{p}(\mathrm{kPa})$ or the specific energy of the pump $Y(\mathrm{~J} / \mathrm{kg})$. Different characteristics of the pumps and piping network are shown in Fig. 1. At the intersection of both characteristics the working point of the pump and piping network can be found. At point $\mathbf{1}$, the pump delivers a mass flow rate $M_{1}$ at operating pressure $\Delta p_{1}$. By reducing the pump mass flow rate $M_{2}$ (for example, by closing highly resistive valves with thermostatic valves), increasing the operation pressure of the pump $\Delta p_{1}$ and then changes the characteristics of the pipeline network and stabilizes the operation point $\mathbf{2}$, respectively $\mathbf{3}$. As a consequence, the flow rate and the differential pressure will increase across the connecting points.

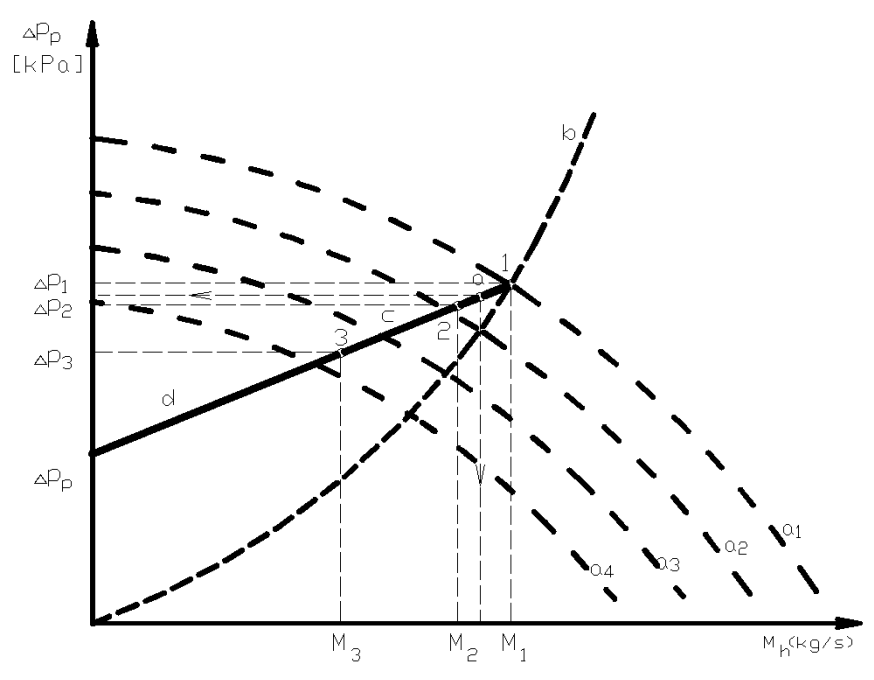

Fig. 1 Working characteristics of a pump and pipeline distribution network $\mathrm{a}$ - pump with a gradual change of speed (1-5), b - characteristics of heating system, $\mathrm{c}$ - pump with constant pressure, $\mathrm{d}$ - pump with a proportional pressure; 1, 2 and 3 - operating points, axis $\Delta p_{p}$ - operating pressure, axis $M_{h}$ - pump mass flow rate

\section{Comparison of some circulating pumps}

The research of a case study was carried out in the residential building in Bratislava (Slovakia). There were two baseline states before and after insulation of building. Thermal insulation covered both exterior walls and roof.

Circulation pump 50 NTR-80-10 was originally installed in the residential building. This pump was embedded in the pipeline. The original condition before the thermal insulation was a mass flow $M_{h, 2}=1.40 \mathrm{dm}^{3} / \mathrm{s}$ and after the thermal insulation, the mass flow was $M_{h, 1}=0.69 \mathrm{dm}^{3} / \mathrm{s}$.

The operational pressure as seen in Fig. 2, was originally $65 \mathrm{~J} / \mathrm{kg}$ (point 2), after the thermal insulation it was behind the area of the stable operation (point 1). Therefore we have compared other circulating pumps to the 50 NTR-80-10 circulating pump [4].

From Fig. 2 we can see that the pump embedded in the piping network was not suitable after the residential building was insulated thermal. The original mass flow is decreased (position 1) so that the pump is operating outside the recommended "area" (line 4). This causes it to operate unreliably and results in problems with balancing the system [5].

When designing a new pump, we consider the following pumps:

- pump $\mathrm{N}^{\circ} 1$. with UPS 40-50 $250 \mathrm{~F}$ steady speeds type, for mass flow $M_{h, 1}=0.69 \mathrm{dm}^{3} / \mathrm{s}=2.5 \mathrm{~m}^{3} / \mathrm{h}, H=2.05 \mathrm{~m}$,

- pump $\mathrm{N}^{\circ}$ 2. with constant pressure type MAGNA 40-100 F, for mass flow $M_{h, 1}=0.69 \mathrm{dm}^{3} / \mathrm{s}=2.5 \mathrm{~m}^{3} / \mathrm{h}, \mathrm{H}=2.05 \mathrm{~m}$,

- pump $\mathrm{N}^{\circ} 3$. with proportional pressure type ALPFA 32-60, for mass flow $M_{h, 1}=0.69 \mathrm{dm}^{3} / \mathrm{s}=2.5 \mathrm{~m}^{3} / \mathrm{h}, H=2.05 \mathrm{~m}$.

The course of the pressure diagram for the original heating system is shown in the diagram. $\mathrm{N}^{\circ}$ 3. (see Fig. 3). 


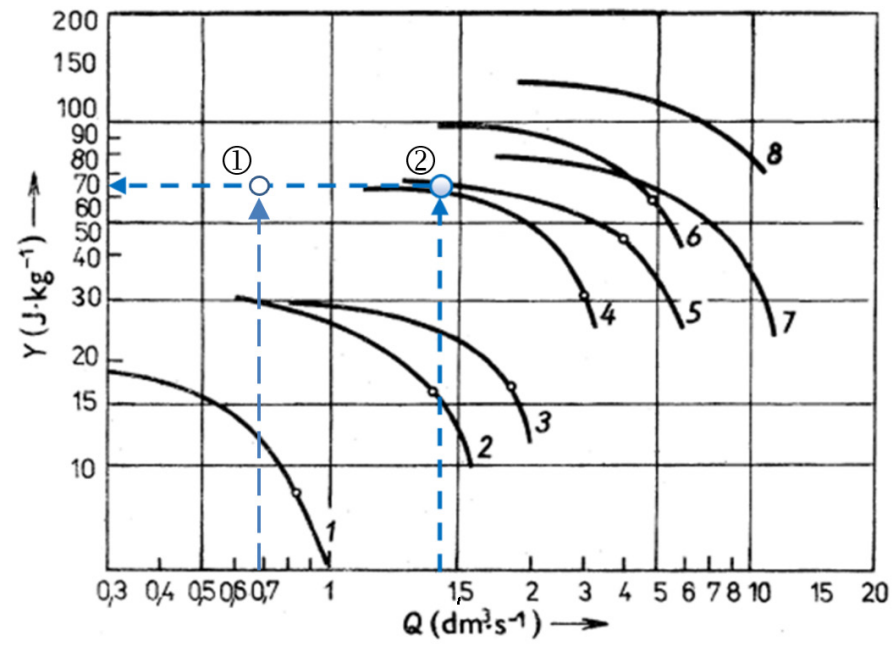

Fig. 2 Working characteristics of the 50 NTR-80-10 pump (line 4) axis $Y$ - specific energy, axis $Q$ - pump mass flow rate (note: $Q=M_{h}$ )

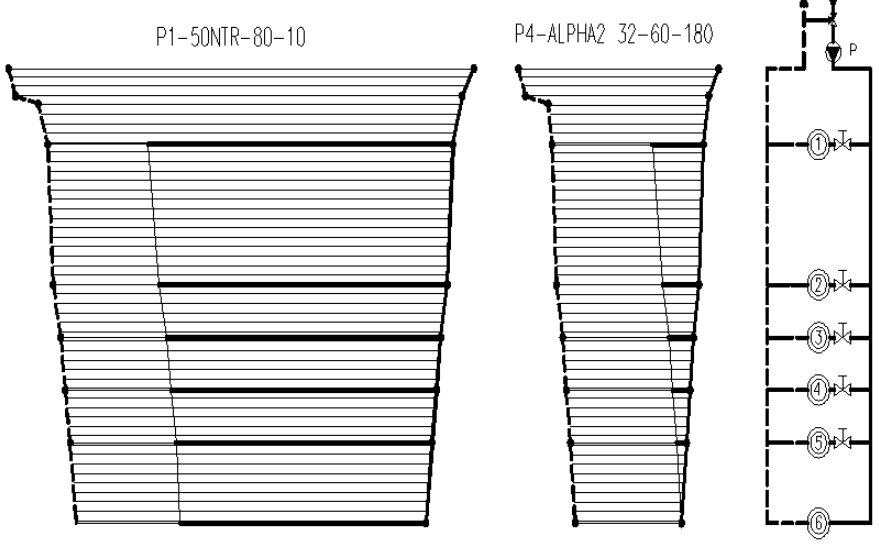

Fig. 4 Pressure diagram of a heating system with an inappropriate and an optimal circulation pump

Price of $1 \mathrm{kWh}$ of electricity was obtained from the operator of the heat source in the residential building.

Operating costs for the 50 NTR-80-10 pump were determined for two modes:

- $\quad \mathrm{N}^{0} 1$. Continuous operation:

$$
\begin{gathered}
P N_{1}=d \times P \times T \times \varepsilon \\
P N_{1}=202 \times 0.36 \times 24 \times 1.0=\mathbf{1 7 4 5 . 3} \mathbf{~ k W h} / \mathbf{y}
\end{gathered}
$$

- $\quad \mathrm{N}^{\circ}$ 2. Intermittent operation:

$$
P N_{2}=202 \times 0.36 \times 24 \times 0.63=\mathbf{1 0 9 9 . 5} \mathbf{k W h} / \mathbf{y}
$$

Fig. 3 Pressure diagram of the heating system with different pumps

From Fig. 3 it is clear, that pumps P3 and P4 have nearly the same pressure diagrams. Only the pressure diagram in pump $\mathrm{N}^{\circ}$ 2. shows higher throttling on the lines into different branches. As an illustration, an inappropriate solution is graphically shown in Fig. 4. The original pump with high pressure is not suitable, because the higher pressure should be on control valve should be throttled. This pressure is causing noise, which reduces the lifetime of the control valves, and has large energy demands. This figure describes why it is important to replace outdated circulation pumps with steady progressive ones with new frequency converters [6].

\section{Economic evaluation of the monitored pumps}

We used a program for dimensioning circulating pumps called "WinCAPS". We calculated the investments and operating costs for the circulating pumps we designed in this program for the city of Bratislava and the length of the heating period $d=202$ days [7]. The values are recorded in Table 1 . where:

$d$ - number of days $(-)$,

$P$ - electrical power (kW); data from the manufacturer's catalog,

$T$ - operating time (hours),

$\varepsilon-$ coefficient of load (-); continuous operation $\varepsilon=1$ (100\% use), intermittent operation $\varepsilon=0.63$ (63\% use).

The return on the investment for the replacement of 50-NTR80-10 the original pump with full-time operations for UPS 40-50 F250 pump is in Table 2.

From the graph (Fig. 5) it is obvious that the return on the investment will be in 2 years (more precisely 1.8 years) taking into account an inflation rate of $5 \%$.

The return on investment for the replacement of the original 50-NTR-80-10 pump with a full-time operation for the MAGNA 40-100F is in Table 3.

From the graph (Fig. 6) it is obvious that the return on investment is in 3 years (more precisely 2.8 years) considering an inflation rate of $5 \%$. 
Table 1 Investments and operating costs for various pumps

\begin{tabular}{|c|c|c|c|c|c|c|}
\hline Order $\mathrm{N}^{\circ}$ & Type of pump & $\mathrm{IC}(€)$ & $\mathrm{EC}(\mathrm{kWh} / \mathrm{y})$ & $\mathrm{PE}(€ / \mathrm{kWh})$ & $\mathrm{OC}(€ / \mathrm{y})$ & $\mathrm{TC}(€ / \mathrm{y})$ \\
\hline 2 - before & 50-NTR-80-10 & 421.40 & 1745.30 & 0.1359 & 237.184 & 658.602 \\
\hline 1 - after & 50-NTR-80-10 & 421.40 & 1099.50 & 0.1359 & 149.426 & 570.844 \\
\hline 3 & UPS-40-50 F250 & 393.10 & 347.00 & 0.1359 & 47.157 & 440.257 \\
\hline 4 & MAGNA 40-100F & 685.40 & 80.00 & 0.1359 & 10.872 & 696.272 \\
\hline 5 & ALPHA 32-60 180 & 281.30 & 66.00 & 0.1359 & 8.969 & 290.269 \\
\hline
\end{tabular}

Note: IC - investments costs, EC - energy consumption, PE - price of energy, OC - operating costs, TC - total costs (IC + OC), $2-$ before thermal insulation, 1 - after thermal insulation

Table 2 Return of investments costs $(€)$ in exchanging the original pump by the new UPS-40-50 F250 pump

\begin{tabular}{lllllllll}
\hline Type of pump & $1^{\text {st }}$ year & $2^{\text {nd }}$ year & $3^{\text {rd }}$ year & $4^{\text {th }}$ year & $5^{\text {th }}$ year & $6^{\text {th }}$ year & $7^{\text {th }}$ year & - \\
\hline 50-NTR-80-10 & 249.0 & 523.0 & 784.5 & 1046.0 & 1307.5 & 1569.0 & 1830.5 & - \\
UPS-40-50 F250 & 422.6 & 492.1 & 541.6 & 591.2 & 640.7 & 690.2 & 739.7 \\
Difference & -193.6 & 30.9 & 242.8 & 454.8 & 666.8 & 878.8 & 1090.8 & - \\
\hline
\end{tabular}

Table 3 Return of investments costs $(€)$ in exchanging the original pump by the new MAGNA 40-100F pump

\begin{tabular}{lllllllll}
\hline Type of pump & $1^{\text {st }}$ year & $2^{\text {nd }}$ year & $3^{\text {rd }}$ year & $4^{\text {th }}$ year & $5^{\text {th }}$ year & $6^{\text {th }}$ year & $7^{\text {th }}$ year & - \\
\hline 50-NTR-80-10 & 249.0 & 523.0 & 784.5 & 1046.0 & 1307.5 & 1569.0 & 1830.5 & - \\
MAGNA 40-100F & 696.8 & 708.2 & 719.6 & 731.1 & 742.5 & 753.9 & 765.3 & - \\
Difference & -447.8 & -185.2 & 64.8 & 314.9 & 565.0 & 815.1 & 1065.2 & - \\
\hline
\end{tabular}

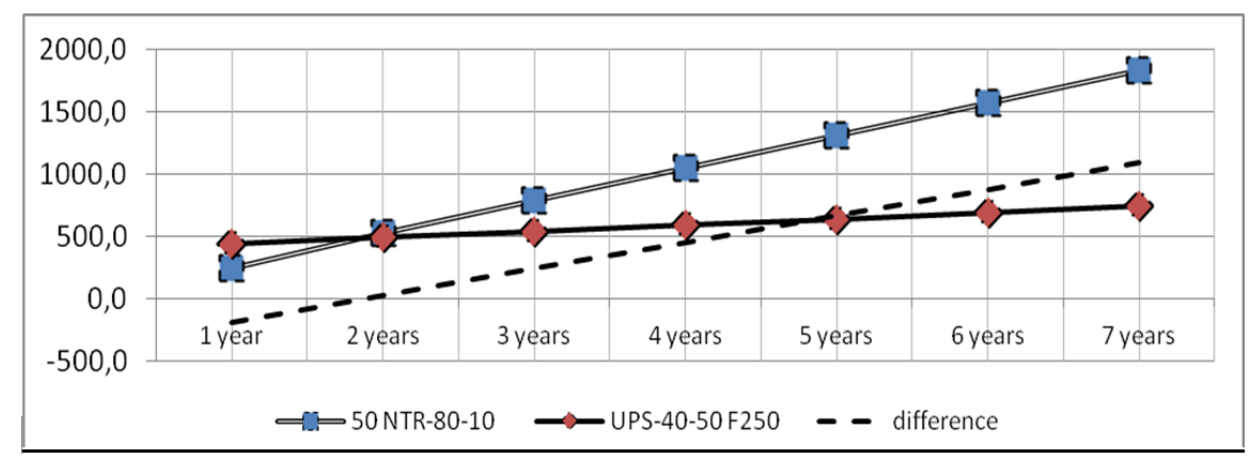

Fig. 5 Return of investments costs (UPS-40-50 F250)

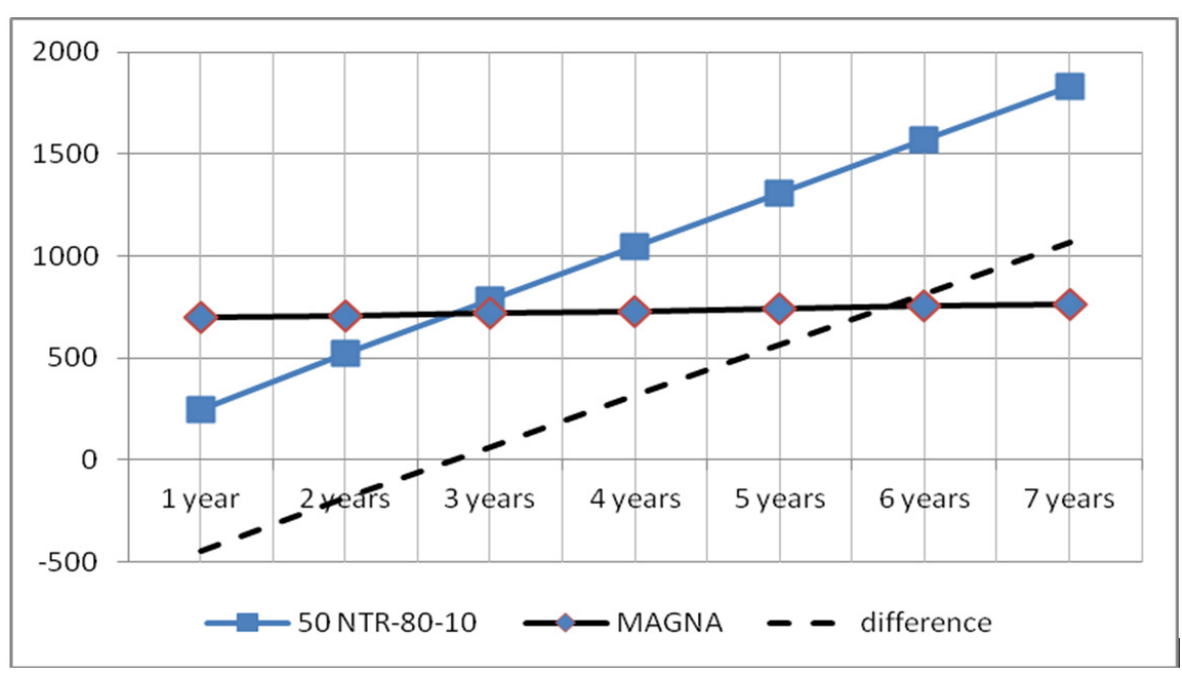

Fig. 6 Return of investments costs (MAGNA 40-100F) 
The return on investment for the replacement of the original 50-NTR-80-10 pump with the full-time operation of the ALPHA 32-60 180 is in Table 4.

From the graph (Fig. 7) it is obvious that the return on investment is in 1 year (more precisely 0.8 year) taking into account an inflation rate of $5 \%$.

If we consider the intermittent operation of the original circulation pump (with the present 0.66), it would increase the return time for the UPS 40-50 F250 to 3.6 years, for the MAGNA 40-100F to 4.6 years and at the ALPHA 32-60 180 pump to 1.6 years. Comparison of the investment and operating costs for the replacement of the pump is shown in Table 5.

From the graph (Fig. 8) it is obvious that the MAGNA 40-100F pump demands a lot of investments costs and is followed by UPS-40-50 F250 pump and ALPHA 32-60 180 pump [8].

Table 4 Return of investments costs $(€)$ in exchanging the original pump by the new ALPHA 32-60 180 pump

\begin{tabular}{lllllllll}
\hline Type of pump & $1^{\text {st }}$ year & $2^{\text {nd }}$ year & $3^{\text {rd }}$ year & $4^{\text {th }}$ year & $5^{\text {th }}$ year & $6^{\text {th }}$ year & $7^{\text {th }}$ year & - \\
\hline 50-NTR-80-10 & 249.0 & 523.0 & 784.5 & 1046.0 & 1307.5 & 1569.0 & 1830.5 & - \\
ALPHA 32-60 180 & 290.7 & 300.1 & 309.6 & 319.0 & 328.4 & 337.8 & 347.2 & - \\
Difference & -41.7 & 222.9 & 474.9 & 727.0 & 979.1 & 1231.2 & 1483.2 & - \\
\hline
\end{tabular}

Table 5 Investments costs $(€)$ and operation costs $(€ / y)$ of pump’s replacement

\begin{tabular}{|c|c|c|c|c|c|c|c|c|c|c|c|c|}
\hline Type of pump & $\mathrm{IC}$ & $\mathrm{OC}$ & $1^{\text {st }}$ year & $2^{\text {nd }}$ year & $3^{\text {rd }}$ year & $4^{\text {th }}$ year & $5^{\text {th }}$ year & $6^{\text {th }}$ year & $7^{\text {th }}$ year & $8^{\text {th }}$ year & $9^{\text {th }}$ year & $10^{\text {th }}$ year \\
\hline UPS-40-50 F250 & 393.1 & 47.2 & 49.51 & 99.03 & 148.54 & 198.06 & 247.57 & 297.09 & 346.60 & 396.12 & 445.63 & 495.15 \\
\hline MAGNA 40-100F & 685.4 & 10.9 & 11.41 & 22.83 & 34.24 & 45.66 & 57.07 & 68.49 & 79.90 & 91.32 & 102.74 & 114.15 \\
\hline ALPHA 32-60 180 & 281.3 & 9.00 & 9.41 & 18.83 & 28.25 & 37.67 & 47.08 & 56.50 & 65.92 & 75.33 & 84.76 & 94.17 \\
\hline
\end{tabular}

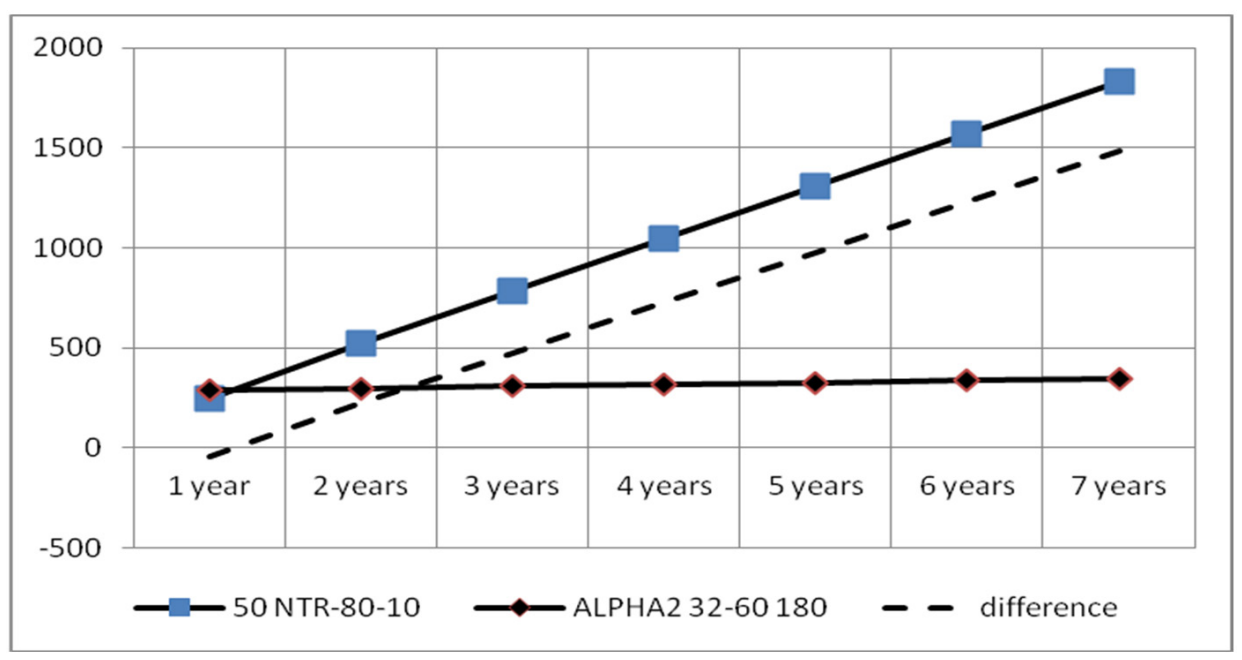

Fig. 7 Return of investments costs (ALPHA 32-60 180)

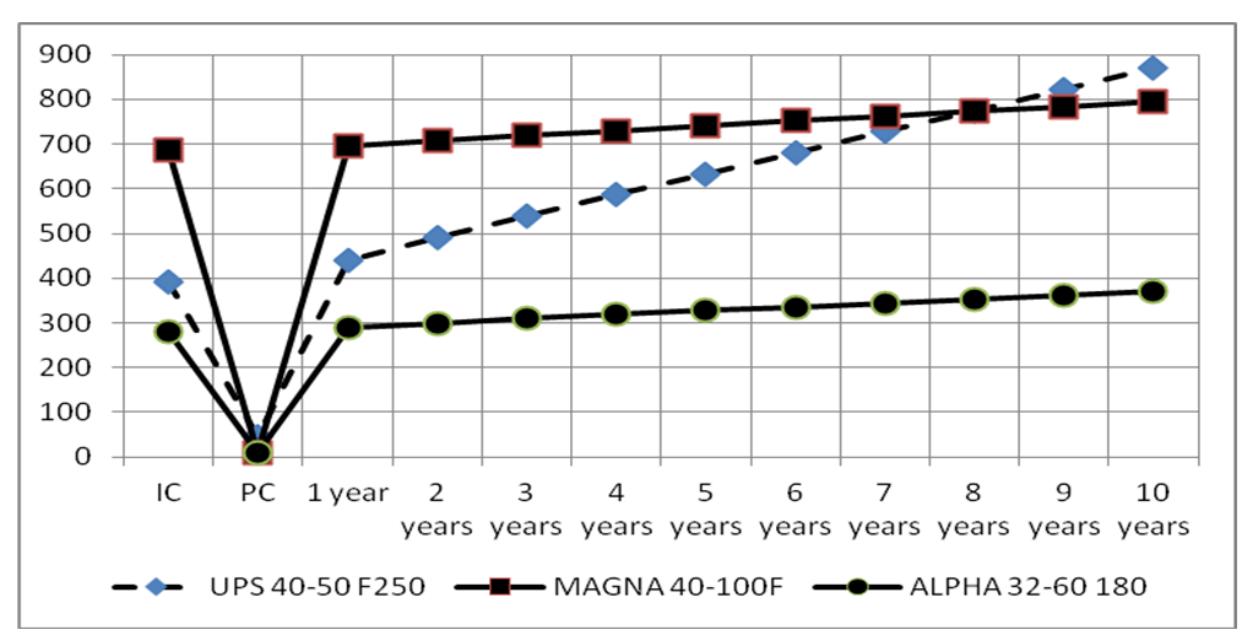

Fig. 8 The amount of the investment 
From an operational perspective, the most demanding pump is UPS-40-50 F250, followed by MAGNA 40-100F pump and ALPHA 32-60 180 pump.

The best for our heating system is pump ALPHA 32-60 180, which has the lowest operating costs $[9,10]$.

\section{Conclusion}

A complex housing renovation leads to a substantial reduction in energy needs for the heating and preparation of domestic hot water. The original equipment of the heating system should be replaced by new, progressive and economically viable elements; we have in mind a new heating system with new pipelines, control valves and heating elements, as well as with sources of active pressures created by progressive circulation pumps with very low power consumption. By using new progressive circulation pumps with a continuous regulation of the speed to maintain static or proportional pressure, we can expect significant savings in the energy required for the operation of the circulation pump. The most significant savings are achieved by changing the speed with frequency converters, which are built into modern progressive pumps. This was confirmed by the analysis of the suitability of the circulation pumps and their operating costs.

\section{Acknowledgement}

This work was supported by the Slovak Research and Development Agency under the Contract No. DS-2016-0030 and by the Ministry of Education, Science, Research and Sport under VEGA Grant 1/0807/17.

\section{References}

[1] Ferstl, K., Masaryk, M. "Prenos tepla." (Heat Transfer.), STU, Bratislava. 2011. (in Slovak)

[2] Kadrnožka, J. "Transformace a kompatibilita termodynamických vlastností pracovních látek." (Transformation and Compatibility of Thermodynamic Properties of Operation Media.), Energetika. 56(11), pp. 362364. 2006. (in Slovak)

[3] Lulkovičová, O., Petráš, D., Kabát, V. "Zdroje tepla a domové kotolne." (Sources of heat and small heat sources.), Jaga group, Bratislava. 2004. (in Slovak)

[4] Kassai, M., Kajtar, L. "Cooling energy saved investigation of air-to-air heat-and energy exchangers." In: Nyers, J., Stuparic, D., Boros, D. (eds.) Proceedings Express 2016, 8th International Symposium, Subotica, Serbia, 31 March - 2 April, 2016, pp. 6-10.

[5] Krajčík, M., Kudiváni, L., Mahdavi, A. "Energy Saving Potential of Personalized Ventilation Applied in an Open Space Office under Winter Conditions." Applied Mechanics and Materials. 861. pp. 417-424. 2017. https://doi.org/10.4028/www.scientific.net/AMM.861.417

[6] Csoknyai, I., Doholuczki, T. "Több, mint hidraulika." (More than hydraulics.), Herz Armatúra Hungária Kft., Budapest. 2013. (in Hungarian)

[7] Skovraard, A. "Grundfos system guide." Onikus kiado Kft., Budapest. 2012.

[8] Bidstrup, N. "What is the Life Cycle Cost of your pumps?" The Magazine for Thinking Buildings. 3(2), 2012. [Online]. Available from: http:// magazines.grundfos.com/Grundfos/blueprint/INT/2012/INTEU/BLUEPRINT2/. [Accessed: 12 January 2017]

[9] Hesterenyi, A. "Mokrobežné a suchobežné čerpadlá: Budúcnost' je vysoko efektívna!." (Wet and dry running pumps: The future is highly effective!,), Ecodesing Directive Magazine of Wilo, HE News. 2010/2011. (in Slovak)

[10] Koudelková, D. "Meranie a regulácia v TZB. 1. čast' - Vykurovanie." (M\&R in HVAC. Part 1 - Heating.), STU, Bratislava. 2014. 